\section{G227(P) STARTING OUT ON A CLINICAL ACADEMIC PATHWAY: THE EXPERIENCE OF A NEWLY - QUALIFIED NURSE}

S Lea, R Taylor, F Gibson. Department of Children's Nursing, London South Bank University, London, UK

\subsection{6/archdischild-2015-308599.220}

Aim The development of clinical academic careers should continue to focus on both clinical and academic work, rather than pursuing one at the expense of the other. What remains a challenge is the articulation of new roles owing to the lack of clarity and shared appreciation of what they are and what they do. As these are relatively new roles, a shared understanding of the activities that clinical academic post holders might undertake have yet to be really clarified. The aim of this work is to reflect upon the experiential learning of a newly - qualified nurse and novice researcher. The focus is on the positive impact of research training on clinical development and vice versa.

Methods A review of the current literature on the topic added to my personal reflection on the benefits and challenges of undertaking a clinical academic career.

Results The literature suggests a lack of clearly defined clinical academic career pathways for nurses during the early stages of their career, which is a key recommendation of the Association of UK University Hospitals (2012). As a result of this, there is a paucity of newly - qualified and junior nurses embarking on a clinical academic pathway. Reflecting on my own experience soon after qualifying of combining a research role within a large research team with clinical practice, there are great benefits to developing both roles early in a career, although there can also be some challenges, one example being the time pressures of juggling two roles.

Conclusion From my experience, I will discuss suggestions to help novice nurses participate in research activity and how to address some of the challenges I have faced, sharing real examples of the benefits. This pathway has been highly dependent on the collaboration between health services and higher education institutions, with support provided from both. I will discuss my support needs as a less experienced nurse juggling two multi-faceted roles. The literature and my personal experience indicate that there would be great benefits to patients, the nursing workforce, and academic and health institutions if more nurses step on to a clinical academic pathway earlier in their career trajectories.

\section{G228 DOES INTEGRATION MAKE A DIFFERENCE TO THE LIVES OF CHILDREN WITH A DISABILITY?}

S Thomas. Family and Therapy Division, Aneurin Bevan University Health Board, Newport, UK

\subsection{6/archdischild-2015-308599.221}

Aims The Integrated Children's Centre provides care, treatment and leisure activities for children with disability and their families under one roof. The aim is that health, social care and the voluntary sector work together to ensure disabled children and their families are supported to participate in valued childhood experiences and have access to the same range of opportunities, life experiences, community services and facilities as other children and their families.

Methods A two year qualitative study with a mixed-method design which included focus groups, interviews and questionnaires was undertaken. Data was gathered from parents/carers and multi - professionals to develop an understanding of what difference an integrated model of care makes to the child with disability and their family.

Results - Increasing skills, knowledge, attitude and behaviour

-Information 'hub' provides improved access to timely, accurate information across networks

- Families better informed resulting in increased skills and confidence

-Meeting parents needs at earlier stage

- Increased staff skill and understanding to deliver family centred care

- Delivering a holistic approach

- Meeting the needs of the whole family

-Formal and informal support for siblings resulting in positive impact on family life

-Change in culture to staff working practice

-Developing a seamless model of care for all levels of need/ disability

- Access to leisure and play

-Increased opportunities for children with a disability to develop, explore and have experiences equal to that of their mainstream peers

-Positive impact on child's clinical care

-Increased and improved life skills, confidence to attend community groups

- Engagement and Empowerment

-Young people have a say and influence service development

-Parents supporting other parents formally and informally

-Active, engaged and empowered parent groups

Conclusion The need for an integrated model of care for children with disability and their families is evident. The positive and beneficial outcomes seen from children/young people and their families and professionals at the Centre, has led to strategic change for children's centres locally and service model is seen as a best practice exemplar nationally.

\section{G229 WHAT MOTHERS DO WHEN THERE IS A CHILD WITH AUTISM AND YOUNGER SIBLINGS IN THE FAMILY: THE IMPLEMENTATION OF THE FINDINGS OF A DOCTORAL STUDY, INTO A HEURISTIC FOR THE CONTINUOUS IMPROVEMENT OF SERVICE USER FAMILY EXPERIENCE}

OS Watt, O Barr, SM O'Neill. School of Nursing, University of Ulster, Derry, UK

\subsection{6/archdischild-2015-308599.222}

Aim The purpose of this abstract is to;

- Present the results of a qualitative research study exploring the experiences of mothers of children with autism and other younger siblings,

- Present the conceptual framework emerging from the results of this research study, which have informed a heuristic, values based model for health and social care service delivery improvement to families raising children with autism and other continuing care needs,

- Introduce this children and young people's rights and values based model, in terms of it's implementation, in the form of a new charitable, membership organisation (Parent Action), which is being developed in Northern Ireland.

Methods In the doctoral research study which is the subject of this abstract, Interpretative Phenomenological Analysis (IPA) was used as methodology and method to explore the experiences of six mothers in Northern Ireland. 
Eighteen semi structured interviews were carried out with the mothers, three with each mother over a twelve month data collection period. Each interview was four to six months apart and all interviews were carried out in the mother's own homes.

Data analysis was carried out on a continuous basis by the researcher, using critical reflection techniques to support the use of the six steps of IPA.

Results Data analysis resulted in six themes of mothers experience, namely; 'Children's Development'; 'Mother's Expertise'; 'Balancing'; Mothers Resilience and Adaptation'; 'Mothers Confidence'; 'Trusted Social Relationships'. The connetions and patterns between these themes, across all six mothers experience, comprise the study conceptual framework.

Conclusion The results of this research have been developed into a children's rights and values based model, which is forming the basis of activities of parent and organisation members of Parent Action. This Parent Action model is represented below.

\section{G230 SUPPORTING PARENTS OF CHILDREN WHO HAVE COMPLEX NEEDS TO ASSESS AND MANAGE THEIR CHILDREN'S PAIN: HEALTH CARE PRACTITIONERS' PERSPECTIVES}

${ }^{1} \mathrm{JM}$ Simons, ${ }^{2} \mathrm{~B}$ Carter, ${ }^{3} \mathrm{~L}$ Bray, ${ }^{4} \mathrm{~J}$ Arnott. ${ }^{1}$ Faculty of Health and Social Care, The Open University, Milton Keynes, UK; ${ }^{2}$ School of Health, University of Central Lancashire, Preston, UK; ${ }^{3}$ Evidence Based Research Centre, Edge Hill University, Ormskirk, UK; ${ }^{4}$ School of Health, University of Central Lancashire, Preston, UK

\subsection{6/archdischild-2015-308599.223}

Aim The aim of this paper is to present findings on the ways in which health care practitioners who work with children with complex needs can support parents in assessing and managing their child's pain.

Methods The data reported here are from semi-structured interviews undertaken with health care practitioners based at a tertiary children's hospital in the UK. These data are part of a larger mixed methods study. Data were analysed using thematic analysis. Results Nineteen healthcare practitioners from a variety of disciplinary backgrounds (e.g. neurologists, nurses, physiotherapists) and with different experience (1-27 years) of working with children with complex needs participated in the study. Only one of the nineteen practitioners interviewed had had formal training on the management of pain in children with complex needs. Practitioners reported taking a multi-layered approach to managing pain in children with complex needs, which meant including parents, using skills of observation and referring to other members of the multidisciplinary team. The practitioners supported parents in the management of their child's pain by engaging with them, listening to them and also managing their expectations, although it was noted that parents' relationships with nurses could be problematic. Most practitioners felt parents had a central role in the management of their child's pain, although it was noted the role could vary and that the multidisciplinary team needed to provide opportunities for parents to give feedback. Practitioners felt that parents had a critical knowledge of their child's pain but not of pain itself. It was suggested that a critical knowledge of their child's pain takes time to develop and that some parents can misread pain cues. Most practitioners felt that parents did not receive adequate training and support to manage their child's pain.

Conclusion Practitioners value the knowledge of parents of children with complex needs and acknowledge the central role parents play in managing their child's pain. However, there is a need for practitioners to have formal education in the management of pain in children with complex needs so that they in turn can provide training and support for parents.

\section{G231 A STUDY TO DETERMINE WHETHER CHANGES IN THE SYSTEM OF CARING FOR CHILDREN AND YOUNG PEOPLE IN A SAME DAY ADMISSION UNIT COULD IMPROVE QUALITY OF CARE WITHOUT ADVERSELY EFFECTING THEATRE UTILISATION}

C Stuart. Puffin Unit, Great Ormond Street Hospital, London, UK

\subsection{6/archdischild-2015-308599.224}

Background The same day admissions unit (SDAU) was formerly an open ward area with no systems in place for admitting up to 45 children a day. No children with learning disabilities were cared for on the unit because it was seen as unsuitable due to the noise and lack of space.

In March 2014 the new SDAU opened with 16 cubicles and a large playroom. This offered the opportunity to be able to bring in systems that would improve quality of care for patients. Admissions were staggered and fasting times were tailored to the admission times to ensure that children were fasted for less time and had less time to wait. We also began to accept Children with learning disabilities onto the unit. The staggered admissions however meant forced breaks in theatre lists.

Aims To examine whether a bringing in an organised system of care was successful in increasing the quality of care to patients and their families without adversely impacting on theatre utilisation.

The main areas of focus were: Patient privacy and dignity, family waiting times, fasting times, family levels of stress and anxiety and being able to provide an improved service for children with learning disabilities.

Method Quantitative data was taken of "patient status at a glance" and PIMS to examine whether fasting and waiting times had been reduced by the new system. The number of patients going through both units was also compared.

Using a questionnaire patient's and their families were able to evaluate their experiences of the new SDAU and compare this with the old unit if they had visited both.

Results The system changes were measured and showed a decrease in waiting and fasting times. Patients and families find the new unit to be calmer and more organised than the old ward and prefer to be cared for in individual cubicles.

Children with learning disabilities are being routinely admitted via SDAU.

Conclusions Good planning involving all the staff was crucial to the change being successful. Communication and using planned and practiced systems was also key. Regular reviewing of systems and being prepared to change them was crucial. The process is still evolving. 